Article

\title{
Phenylmethimazole Blocks dsRNA-Induced IRF3 Nuclear Translocation and Homodimerization
}

\author{
Maria C. Courreges ${ }^{1}$, Noriko Kantake ${ }^{1,2}$, Douglas J. Goetz ${ }^{3,4}$, Frank L. Schwartz ${ }^{1,3,5}$ \\ and Kelly D. McCall ${ }^{1,3,5,6,7, *}$
}

1 Department of Specialty Medicine, Ohio University, Athens, OH 45701, USA

2 Interthyr Corporation, Athens, OH 45701, USA

3 Biomedical Engineering Program, Ohio University Russ College of Engineering \& Technology, Ohio University, Athens, OH 45701, USA

4 Department of Chemical and Biomolecular Engineering, Ohio University Russ College of Engineering \& Technology, Ohio University, Athens, OH 45701, USA

5 Diabetes Institute, Ohio University College of Osteopathic Medicine, Ohio University, Athens, $\mathrm{OH} 45701$, USA

6 Department of Biological Sciences, Ohio University College of Arts \& Sciences, Ohio University, Athens, OH 45701, USA

7 Molecular \& Cellular Biology Program, Ohio University College of Arts \& Sciences, Ohio University, Athens, OH 45701, USA

* Author to whom correspondence should be addressed; E-Mail: mccallk@ohio.edu; Tel.: +1-740-593-0926; Fax: +1-740-597-1371.

Received: 5 October 2012; in revised form: 16 October 2012 / Accepted: 19 October 2012 /

Published: 22 October 2012

\begin{abstract}
Previous studies revealed that phenylmethimazole (C10) inhibits IRF3 signaling, preventing dsRNA-induction of type 1 interferon gene expression, production, and downstream signaling. In the present study, we investigated the molecular basis for $\mathrm{C} 10$ inhibition of dsRNA-stimulated IRF3 signaling. IRF-3 Trans-AM assays were used to measure $\mathrm{C} 10$ effects on dsRNA induction of IRF3 DNA binding. Green fluorescent protein-labeled IRF3 was used to measure C10 effects on dsRNA-induced IRF3 nuclear translocation. Native PAGE, SDS PAGE, and western blotting were used to identify effects of $\mathrm{C} 10$ on IRF3 homodimer formation and phosphorylation, respectively. There was a significant impairment of dsRNA-induced IRF3 DNA binding activity in human embryonic kidney and pancreatic cancer cells with $\mathrm{C} 10$ treatment. C10 also blocked dsRNA-induced IRF3 nuclear translocation and homodimer formation without blocking
\end{abstract}


serine 396 phosphorylation of IRF3. Together, these results indicate that C10 interferes with IRF3 signaling by blocking dsRNA-induced IRF3 homodimer formation, a prerequisite for nuclear translocation and DNA binding activities.

Keywords: phenylmethimazole (C10); IRF3

\section{Introduction}

Interferon regulatory factor 3 (IRF3) is a critical mediator of innate immune signaling. IRF3 is activated in response to viral infection or presence of dsRNA in the cytoplasm. In particular, activation of IRF3 by dsRNA, induces serine/threonine phosphorylation of IRF3 near the carboxy-terminus, which leads to the homodimerization of activated IRF3 and translocation of the IRF3 homodimer from the cytoplasm to the nucleus [1-3]. In the nucleus the activated IRF3 homodimer complexes with the chaperone proteins CBP and p300, binds to its transcriptional regulatory DNA sequences, and initiates the activation of target gene transcription [i.e., type 1 interferons (IFN $\alpha$ and IFN $\beta$ ), RANTES, IL-15, ISG50] [1-9].

The innate immune response to pathogenic infectious agents is initiated by pattern recognition receptors (PRRs) which recognize pathogen-associated molecular patterns (PAMPs) such as viral dsRNA [10-14]. Currently identified PRRs which recognize cytoplasmic dsRNA and activate IRF3 include toll-like receptor 3 (TLR3), retinoic acid-inducible gene 1 (RIG1), and melanoma differentiation associated factor 5 (MDA5). dsRNA-activated TLR3 interacts with Toll/IL-1 receptor (TIR)-domain-containing adaptor inducing IFN-beta (TRIF), which will subsequently interact with tumor necrosis factor (TNF)R-associated factor 3 (TRAF3) [15]. TRAF3 will then undergo self-ubiquitination to activate TRAF family member-associated NF-kB activator (TANK)-binding kinase 1 (TBK1) and/or inducible IKK (IKK-i) [16]. Activated TBK1 or IKK- $i$ will then activate IRF3 [10,15-20]. The RIG-1-like receptor (RLR) family members, RIG1 and MDA5 undergo conformational changes following binding of dsRNA and expose their caspase recruitment domains (CARDs) [10,21,22]. The CARDs of RIG1 and MDA5 will then interact with the CARD-containing adaptor protein IPS1 (a mitochondrial outer membrane protein also known as MAVS, Cardif, and VISA) that will subsequently activate TRAF3, which in turn activates TBK1 and/or IKK- $i$, which then activates IRF3 [10,17-20,23-29].

While IRF3 signaling is important for mediating the innate immune response, pathologic IRF3 signaling, via abnormal TLR signaling in non-immune cells for example, can lead to the development of autoimmune and inflammatory diseases such as diabetes (Types 1 and 2), atherosclerosis, autoimmune thyroid disease, inflammatory bowel disease, sepsis, and even cancer [30-45]. Since autoimmune and inflammatory diseases arising from abnormal TLR signaling afflict millions of individuals worldwide, compounds that inhibit pathologic TLR expression and signaling may be particularly useful as a novel therapeutic approach for these pathologies.

Previous studies have revealed that phenylmethimazole (C10) (structure has been previously described [46]) acts primarily to inhibit dsRNA-triggered IRF3 signaling, preventing dsRNA-induction of type 1 interferon gene expression, type 1 interferon production, and type 1 interferon signaling 
without cellular toxicity $[32,33]$. However, the mechanism by which C10 blocks IRF3 transcriptional activity is currently unknown. The studies described herein were designed to explore the molecular basis for C10 inhibition of dsRNA-mediated IRF3 signaling.

\section{Results and Discussion}

\subsection{C10 Inhibits IRF3 DNA Binding in Human Embryonic Kidney and Pancreatic Cancer Cells}

In order to study the effect of C10 on IRF3 DNA binding activity in human cells, human embryonic kidney 293 (HEK293) cells which stably overexpress human TLR3 tagged with hemagglutinin (HA), HEK293-hTLR3-HA cells, and human pancreatic cancer cells (PANC-1) were transfected with pUNO-hIRF3 as described in the Experimental section. Twenty four h later, cells were incubated with polyinosinic-polycytidylic acid (poly I:C) in the presence or absence of $0.5 \mathrm{mM} \mathrm{C10}$. Six $\mathrm{h}$ after stimulation, nuclear proteins were obtained and DNA binding activity was quantified using an ELISA based assay (TransAM transcription factor assay, Active-motif). As shown in Figure 1, C10 treatment produced a significant impairment of the DNA binding activity of IRF3 in both cell types tested which was in agreement with previously reported inhibition of poly I:C-induced IFN transcription in C10 treated cells [33].

It is interesting to note that while $\mathrm{C} 10$ significantly blocked poly I:C-induced IRF3 activity in both cell types, C10 completely abolished poly I:C-induced IRF3 activity as well as reduced IRF3 activity below basal levels in PANC-1 cells, whereas C10 only partially blocked poly I:C-induced IRF3 activity in 293-hTLR3-HA cells (Figure 1). Observations from Figure 1 may help to explain these differences. First, PANC-1 cells have much higher basal IRF3 activation than 293-hTLR3-HA cells (basal IRF3 activity in PANC-1 cells is roughly twice that of 293-hTLR3-HA cells). Second, poly I:C stimulates IRF3 activity to a much greater extent in 293-hTLR3-HA cells than it does in PANC-1 cells ( 4-fold in 293-hTLR3-HA cells, versus $\sim$ two-fold in PANC-1). The higher basal activity of IRF3 in PANC-1 cells (Figure 1) as well as our previous reports that PANC-1 cells basally express much higher levels of IFN $\beta$ than HEK293 cells [31], suggests possible chronic activation of endogenous dsRNA-sensing pathways which may be causing the blunted response to exogenous dsRNA (i.e., poly I:C) observed in PANC-1 cells compared to 293-hTLR3-HA cells. In contrast, the lack of basal dsRNA-sensing pathway activity in 293-hTLR3-HA cells as suggested by the observed low basal activity of IRF3 in 293-hTLR3-HA cells, allows for a more dramatic activation of IRF3 activity by exogenous dsRNA (i.e., poly I:C). Since C10 indiscriminately blocks dsRNA activation of IRF3, whether endogenous or exogenous, it makes sense that we would see inhibition of both poly I:C-stimulated IRF3 activity as well as basal IRF3 activity in PANC-1 cells. PANC-1 cells are derived from a human pancreatic carcinoma [47] and thus may contain viral dsRNA or dsRNA of self-origin from cellular damage, which could explain their high basal IRF3 activity. In contrast, 293-hTLR3-HA cells are derived from normal human embryonic kidney cells [48] and are stably transfected with the human TLR3 gene fused to the influenza hemaglutinine (HA) tag. Thus, 293-hTLR3-HA cells over-express human TLR3 at very high levels which may also help explain why they have a more pronounced response to poly I:C. In addition, the partial inhibition of poly I:C-induced IRF3 activation by C10 
observed in 293-hTLR3-HA cells may be due to the artificial over-amplification of the TLR3 pathway in these cells.

Figure 1. C10 inhibits IRF3 activation in human cell lines. 293-hTLR3-HA (A) and PANC-1 (B) cells were stimulated with $100 \mu \mathrm{g} / \mathrm{mL}$ Poly I:C during $6 \mathrm{~h}$ in the presence or absence of $\mathrm{C} 10$ or vehicle (DMSO). IRF3 binding activity in nuclear extracts (5 $\mu \mathrm{g}$ or $10 \mu \mathrm{g}$ protein respectively) was determined using an ELISA-based technique. Results are presented as mean \pm SD from 3 biological replicates. Significance was determined using one-way ANOVA followed by Tukey's multiple comparison test. ${ }^{*} p<0.05$ between groups as indicated. All poly I:C treatment groups were statistically different than untreated and lipofectamine control groups, $p<0.05$.

A

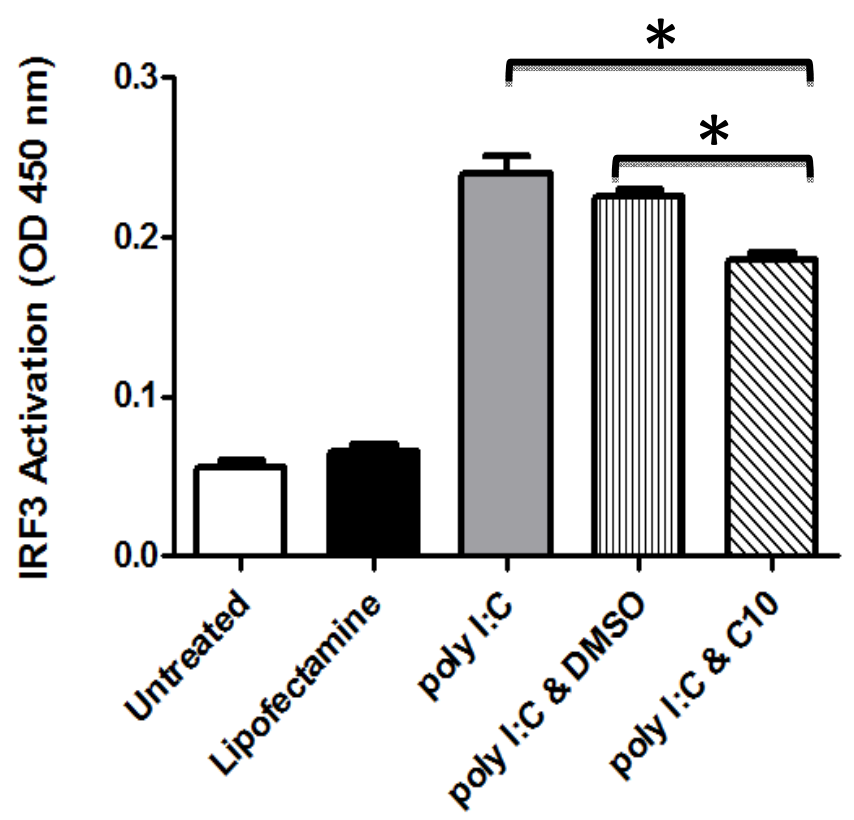

B

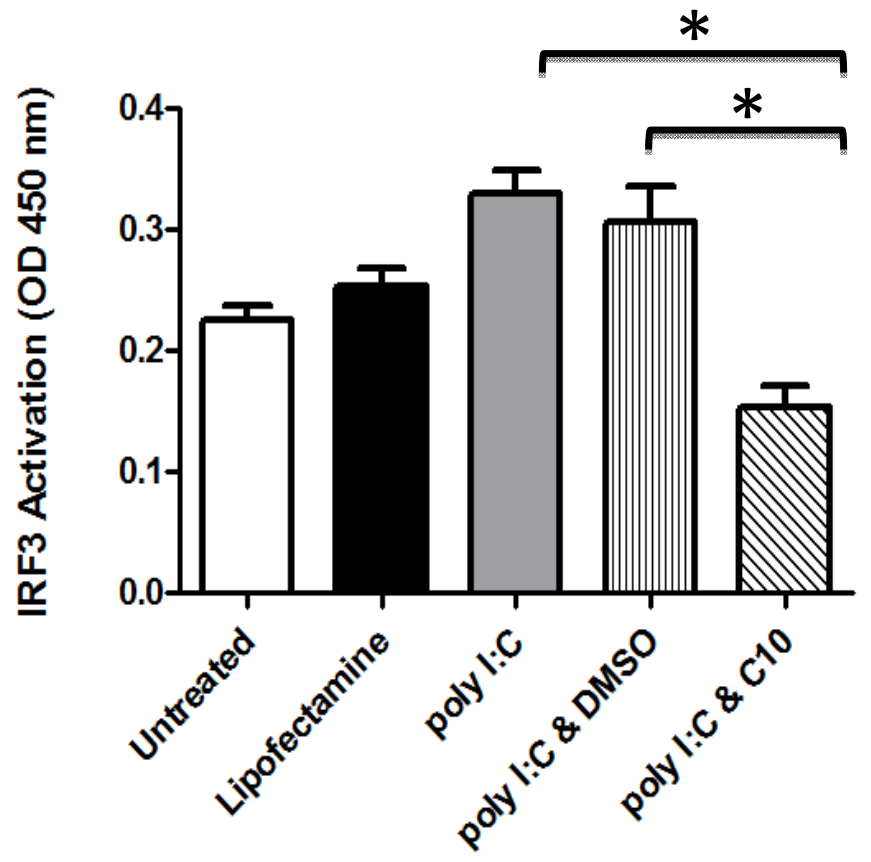




\subsection{C10 Inhibits IRF3 Translocation to the Nucleus}

In order to establish if $\mathrm{C} 10$ was able to block the translocation of activated IRF3 to the nucleus, we used a green fluorescent protein (GFP)-IRF3 fusion protein kindly provided by Dr. Christopher Basler, Mt. Sinai School of Medicine, and which has been used to measure dsRNA-stimulated IRF3 nuclear translocation [49]. Briefly, PANC-1 cells were grown in chamber slides and transfected with $100 \mathrm{ng}$ pEGFP-C1-hIRF3, a plasmid which overexpresses green fluorescent protein (GFP) fused to human IRF3. Twenty-four h later, cells were transfected with poly I:C $(1 \mu \mathrm{g} / \mathrm{mL})$ in the presence or absence of $\mathrm{C} 10$, and incubated for $6 \mathrm{~h}$ before fixation and counterstaining and examination under a fluorescent microscope. In all cases, proper controls were run (Untreated or Lipofectamine 2000 only). As shown in Figure 2, PANC-1 cells displayed a strong cytoplasmic fluorescence upon transfection with pEGFP-C1-hIRF3. Stimulation of the TLR3 signaling pathway with poly I:C caused the translocation of the fluorescence to the nucleus, indicating translocation of the activated IRF3 homodimer to the nucleus. This translocation was completely blocked by $\mathrm{C} 10$ treatment (Figure 2), indicating that C10 blocked translocation of the activated IRF3 homodimer to the nucleus. Similar results were obtained with HEK293-hTLR3-HA cells (data not shown).

Figure 2. C10 inhibits IRF3 translocation to nucleus. PANC-1 cells were transfected with an expression plasmid for GFP-IRF3. Transfected cells were stimulated with poly I:C in the presence or absence of $\mathrm{C} 10$ or vehicle (DMSO). Cells were fixed in $4 \%$ formaldehyde and nuclei were stained with DAPI. The sub cellular location of GFP tagged IRF3 was analyzed with an Olympus fluorescence microscope.

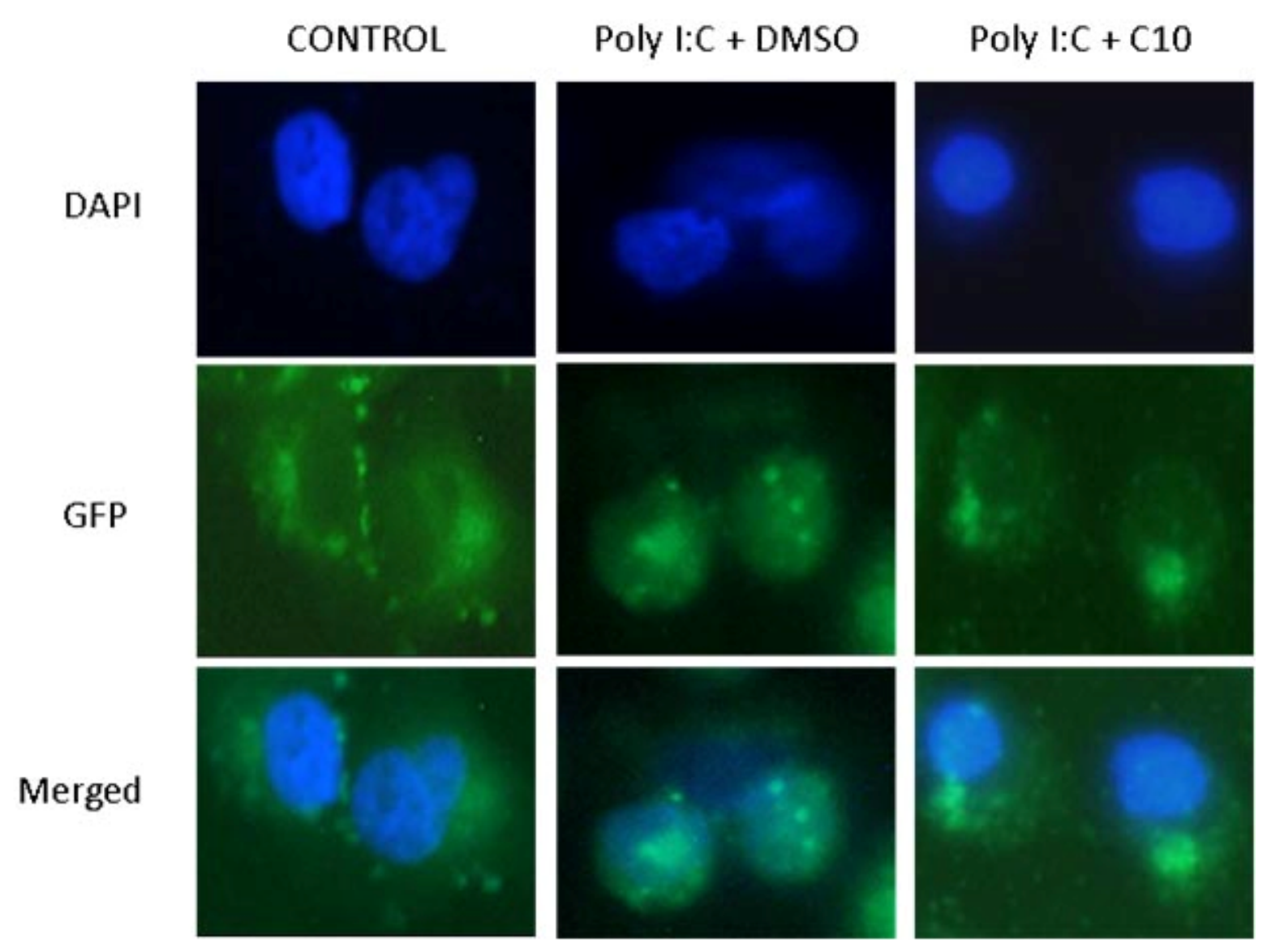




\subsection{C10 Inhibits IRF3 Homodimer Formation}

Activation of TLR3 signaling by dsRNA induces serine/threonine phosphorylation of IRF3 near the carboxy-terminus, which leads to the homodimerization of activated IRF3 in the cytoplasm. This event is followed by translocation of the IRF3 homodimer to the nucleus where it will make a complex with specific chaperone proteins and bind to its transcriptional DNA regulatory sequence to initiate transcription of target genes [i.e., type 1 interferons (IFN $\alpha$ and IFN $\beta$ ), RANTES, IL-15, ISG56] [1,2,5-8].

If $\mathrm{C} 10$ prevents the IRF3 homodimer from entering the nucleus, the compound may be interfering with the translocation itself or with an upstream signaling event. In order to study any upstream effects of C10 on dsRNA-induced IRF3 homodimerization, we performed native polyacrylamide gel electrophoresis (PAGE) followed by Western blotting to analyze proteins isolated from PANC-1 cells that were treated with and without C10. Briefly, PANC-1 cells were transfected with poly I:C $(1 \mu \mathrm{g} / \mathrm{mL})$ and incubated with or without $\mathrm{C} 10$ for $6 \mathrm{~h}$. Cellular proteins were collected and separated on a $7.5 \%$ non-denaturing polyacrylamide gel with $1 \%$ deoxycholate in the cathode buffer as described [50]. IRF3 monomers and dimers were detected by Western Blot analysis using anti-IRF3 antibody. As shown in Figure 3, proteins from resting cells showed only an IRF3 monomer band while the stimulation with poly I:C was associated with an additional homodimer band. Protein extracts obtained from C10-treated cells showed a significant reduction in the intensity of the homodimer band. These results suggest that $\mathrm{C} 10$ treatment interferes with dsRNA-stimulated IRF3 homodimer formation.

Figure 3. C10 inhibits IRF3 homodimer formation. (A) PANC-1 cells were stimulated with poly I:C in the presence or absence of $\mathrm{C} 10$ or vehicle (DMSO). Total proteins extracts were separated on a $7.5 \%$ nondenaturing polyacrylamide gel with $1 \%$ deoxycholate in the cathode buffer. Monomers and dimers were detected by Western Blot analysis using anti-IRF3 antibody. Images shown are representative immunoblots from 3 biological replicates. (B) Average relative intensity of dimer to monomer band. Results are presented as mean \pm SD from 3 biological replicates. Significance was determined using one-way ANOVA followed by Tukey's multiple comparison test. ${ }^{*} p<0.05$ between groups as indicated. All poly I:C treatment groups were significantly different than untreated control group, $p<0.05$.

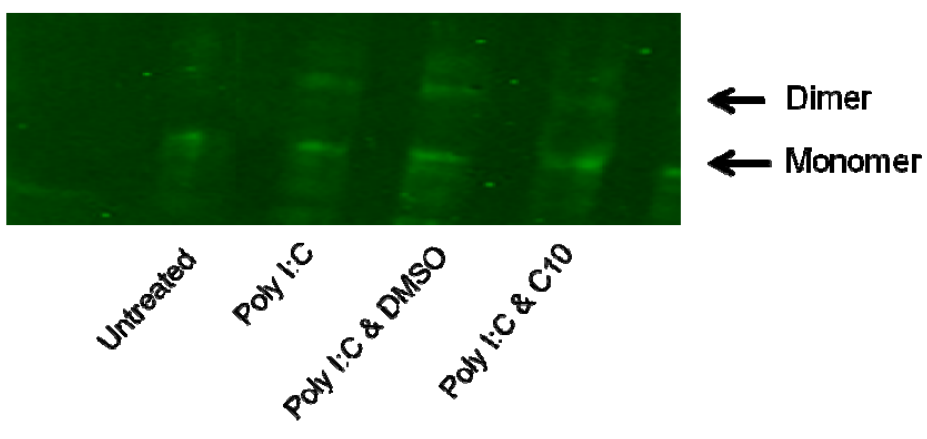

(A)

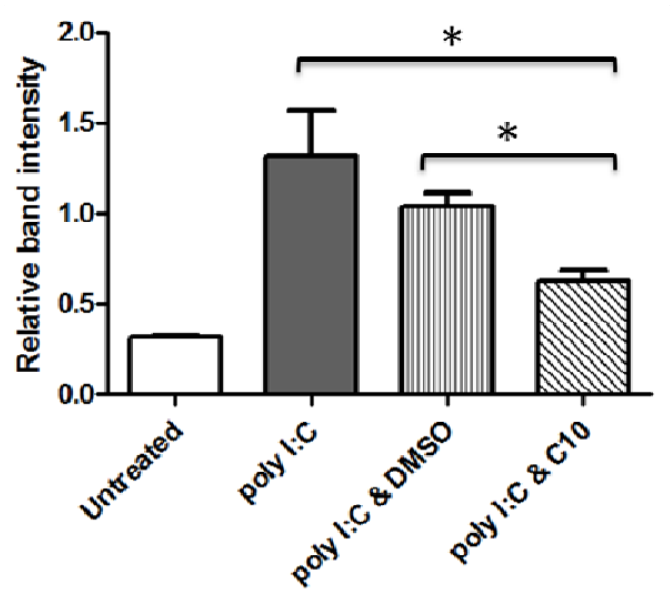

(B) 


\subsection{C10 Does Not Affect IRF-3 Phosphorylation}

IRF3 is post-translationally modified by phosphorylation at multiple serine and threonine residues located in the carboxy terminus of IRF3. Point mutations of residues Ser396 and Ser398 eliminated virus-induced phosphorylation and nuclear translocation of IRF3 protein [51], establishing their importance in this pathway. Given that IRF3 phosphorylation is a necessary event that precedes the formation of the IRF3 homodimer, we subsequently evaluated effects of C10 on dsRNA-stimulated IRF3 phosphorylation. To accomplish this, we activated TLR3 signaling using poly I:C transfection in PANC-1 and HEK293-hTLR3-HA in the presence or absence of C10 and proper controls. Total proteins were analyzed by Western blotting to evaluate total or serine 396 phosphorylated IRF3. As shown in Figure 4, C10 did not block dsRNA-induced phosphorylation of IRF3 at serine residue 396 in any of the cell types tested. Taking into account that IRF3 has multiple phosphorylation sites [51], this negative result does not rule out that phosphorylation in other residues can be affected by $\mathrm{C} 10$.

Figure 4. C10 does not inhibit IRF3 phosphorylation of Ser 396. (A) PANC-1 cells were stimulated with poly $\mathrm{I}: \mathrm{C}$ in the presence or absence of $\mathrm{C} 10$ or vehicle (DMSO). Total protein extracts were separated using denaturing SDS PAGE. Total IRF3 and Ser 396 phosphorylated IRF3 were detected by Western Blot analysis using anti-IRF3 and anti-phospho-Ser 396 IRF3 antibodies. Images shown are representative immunoblots from 3 biological replicates. (B) Average relative intensity of phospho-IRF3 to beta actin after Odyssey scanning. Results are presented as mean \pm SD from 3 biological replicates. Significance was determined using one-way ANOVA followed by Tukey's multiple comparison test. * Indicates significant difference from untreated and lipofectamine control groups as indicated, $p<0.002$. There was no significant difference between poly I:C, poly $\mathrm{I}: \mathrm{C} \& \mathrm{DMSO}$, and poly I:C \& C10 groups.

A



B



It is noteworthy to mention that no cellular toxicity was observed in 293-hTLR3-HA or PANC-1 cells treated with $\mathrm{C} 10$ in these studies, an observation in agreement with our previous report using $\mathrm{C} 10$ at the same concentration in PANC-1 and HEK293 cells [31]. Data presented in Figure 2 indicate that cellular morphology of C10-treated cells is identical to control cells, confirming the absence of cellular 
toxicity. In addition, data in Figure 4 show that the internal control (beta actin) protein expression is unaffected by $\mathrm{C} 10$ treatment also indicative of the absence of cellular toxicity associated with C10 treatment.

\section{Experimental}

\subsection{Phenylmethimazole (C10) Solutions}

Phenylmethimazole was provided by the Interthyr Corporation. C10 was prepared as a fresh $200 \mathrm{mM}$ stock solution in $100 \%(\mathrm{v} / \mathrm{v}) \mathrm{DMSO}$, and further diluted into medium to achieve the concentrations indicated in individual experiments.

\subsection{Cell Culture}

All experiments were performed with 293-hTLR3-HA (InvivoGen) and PANC-1 cells, generously provided by Dr. Duxin Sun (The Ohio State University). 293-hTLR3-HA cells were cultured in DMEM (Invitrogen) containing 10\% (v/v) fetal bovine serum (ATLAS) and $10 \mu \mathrm{g} / \mathrm{mL}$ blasticidin (InvivoGen). PANC 1 cells were grown in the same basal media containing $10 \%(\mathrm{v} / \mathrm{v})$ fetal bovine serum (ATLAS), $100 \mathrm{U} / \mathrm{mL}$ penicillin and $100 \mu \mathrm{g} / \mathrm{mL}$ streptomycin (Invitrogen). Both cell lines were grown at $37{ }^{\circ} \mathrm{C}$ with $5 \% \mathrm{CO}_{2}$.

\subsection{Plasmids and Transfections}

pEGFP-IRF3 plasmid was kindly provided by Dr. Christopher Basler (Mount Sinai School of Medicine) and was used for IRF3 nuclear translocation assays [49]. For IRF3 phosphorylation experiments, pUNO-hIRF3-HA plasmid (InvivoGen) was used. All transfections were performed using Lipofectamine 2000 (Invitrogen) with standard protocol provided by the manufacturer.

\subsection{Preparation of Nuclear Extracts for IRF-3 DNA-Binding Activity}

293-hTLR3-HA and PANC-1 were used to study IRF3 DNA-binding activity. For these purposes, cells were grown to $70 \%$ confluence in $10 \mathrm{~mm}^{2}$ dishes and transfected with $100 \mathrm{ng}$ pUNO-hIRF3 per dish. Twenty four h after transfection, cells were stimulated with $100 \mu \mathrm{g} / \mathrm{mL}$ poly I:C in the presence or absence of $0.5 \mathrm{mM} \mathrm{C10}$. Six h after stimulation nuclear proteins were obtained using a Nuclear Extraction Kit (Active Motif) and protein concentration was quantified using the Micro BCA Protein Assay kit (Thermo Scientific).

\subsection{Detection of IRF-3 DNA-Binding Activity}

IRF3 binding activity in nuclear extracts was measured with an ELISA based assay (Trans-AM IRF3 transcription, Active Motif) according to the manufacturer's protocol. Nuclear extracts (5 $\mu \mathrm{g}$ for 293-hTLR3-HA cells or $10 \mu \mathrm{g}$ for PANC-1) were incubated on plates coated with ISRE consensus oligonucleotide. Following incubation and extensive washes, the quantity of bound transcription factor was then determined by use of a specific primary antibody and a secondary antibody conjugated to horseradish peroxidase in an ELISA-based format. The intensity of the reaction was measured at $450 \mathrm{~nm}$. 


\subsection{Translocation of IRF-3 to the Nucleus}

In order to further assess the mechanism by which C10 prevented IRF3 transcriptional activity, we proposed to determine whether $\mathrm{C} 10$ had an effect on translocation of activated IRF3 to the nucleus following poly I:C activation of the TLR3 signaling pathways using a GFP-IRF3 fusion as previously reported [49]. To accomplish this, 293-hTLR3-HA and PANC-1 cells were grown in 8 well chamber slides to 70-80\% confluence. Cells were then transfected with 100 ng pEGFP-hIRF3, a plasmid which overexpresses green fluorescent protein (GFP) fused to human IRF3. Twenty-four h later, cells were transfected with poly I:C $(1 \mu \mathrm{g} / \mathrm{mL})$, and incubated for $6 \mathrm{~h}$ in the presence or absence of $\mathrm{C} 10$ or DMSO. In all cases, proper controls were run (Untreated or Lipofectamine 2000 only). Cell monolayers were rinsed with cold PBS, fixed for 5 minutes with $4 \%$ formalin and counter stained with 4',6-diamidino-2-phenylindole, dihydrochloride (DAPI) for nuclear localization of the IRF3 signal and then examined under fluorescent microscopy.

\subsection{SDS and Native PAGE Analyses}

PANC-1 cells were grown on $10 \mathrm{~cm}$ dishes to confluence. Cells were transfected or not with poly $\mathrm{I}: \mathrm{C}(1 \mathrm{ug} / \mathrm{mL})$ to induce IRF3 phosphorylation in the presence or absence of C10. Six h later, whole cell extracts were isolated. Briefly, cells were washed in ice-cold phosphate-buffered saline before being lysed on ice in buffer $(10 \mathrm{mM}$ Tris-HCl pH 7.5,150 mM NaCl, 1\% Nonidet P-40 (v/v) and protease inhibitor cocktail (set III EDTA free, Calbiochem). The cell lysates were centrifuged at 13,000 rpm for $15 \mathrm{~min}$. Protein concentration in supernatants (whole cell extracts, WCE) was determined using micro BCA Protein Assay kit (Thermo Scientific) according to manufacturer's instructions.

For SDS-PAGE, $10 \mu \mathrm{g}$ of protein extracts per lane were electrophoresed on $4-12 \%$ acrylamide gradient bis-Tris gels (Invitrogen). Native PAGE electrophoresis in order to study IRF3 dimer formation was performed as described previously [50]. Briefly, 7.5\% acrylamide gels without SDS (Bio-Rad) were pre-run with $25 \mathrm{mM}$ Tris and $192 \mathrm{mM}$ glycine, $\mathrm{pH} \mathrm{8.4,} \mathrm{with} \mathrm{and} \mathrm{without} \mathrm{1 \%}$ deoxycholate (Sigma) in the cathode and anode chamber, respectively, for $30 \mathrm{~min}$, at $40 \mathrm{~mA}$. WCEs $(10 \mu \mathrm{g})$ diluted in the native sample buffer $(62.5 \mathrm{mM}$ Tris-HCl, $\mathrm{pH} 6.8,15 \%$ glycerol, and bromophenol blue) were applied to the gel and subjected to electrophoresis for $60 \mathrm{~min}$ at $25 \mathrm{~mA}$.

Proteins were transferred to nitrocellulose membranes, blocked with LI-COR blocking buffer and incubated with primary antibody (anti-total IRF3 and anti-Phospho Ser 396 IRF3, Cell Signaling) followed by appropriate secondary antibody. All antibody dilutions were performed in LI-COR blocking buffer supplemented with $0.2 \%$ Tween 20 (Calbiochem). Membranes were scanned using the Odyssey Infrared Imaging System (LI-COR)

\subsection{Statistical Analysis}

All experiments were replicated at least three times on different groups of cells. All data were expressed as mean \pm SD. One-way ANOVA followed by Tukey's multiple comparison test were used to evaluate statistical significance of the results with GraphPad Instat. 


\section{Conclusions}

The results described herein indicate that phenylmethimazole (C10) interferes with dsRNA-induced IRF3 signaling specifically by (1) preventing DNA binding activity of IRF3; (2) blocking dsRNA-induced IRF3 translocation to the nucleus; and (3) impairing IRF3 homodimer formation, a prerequisite for nuclear translocation. $\mathrm{C} 10$ does not, however, affect phosphorylation of IRF3 at serine residue 396 in PANC-1. Future work will focus on determining whether or not C10 binds IRF3 directly to prevent homodimerization, or if $\mathrm{C} 10$ blocks IRF3 homodimer formation by blocking an essential phosphorylation and/or other post-translational modification necessary for IRF3 homodimer formation.

\section{Acknowledgments}

This work was supported by a National Institutes of Health Small Business Technology Transfer (STTR) grant (GRANT00550937) and by the Interthyr Corporation.

This manuscript is dedicated to the late Leonard D. Kohn, without whom this work would not have been possible.

\section{References}

1. Lin, R.; Heylbroeck, C.; Pitha, P.M.; Hiscott, J. Virus-dependent phosphorylation of the IRF-3 transcription factor regulates nuclear translocation, Transactivation potential, and proteasome-mediated degradation. Mol. Cell Biol. 1998, 18, 2986-2996.

2. Yoneyama, M.; Suhara, W.; Fukuhara, Y.; Fukuda, M.; Nishida, E.; Fujita, T. Direct triggering of the type I interferon system by virus infection: Activation of a transcription factor complex containing IRF-3 and CBP/p300. EMBO J. 1998, 17, 1087-1095.

3. Lin, R.; Mamane, Y.; Hiscott, J. Structural and functional analysis of interferon regulatory factor 3: Localization of the transactivation and autoinhibitory domains. Mol. Cell. Biol. 1999, 19, 2465-2474.

4. Grandvaux, N.; Servant, M.J.; tenOever, B.; Sen, G.C.; Balachandran, S.; Barber, G.N.; Lin, R.; Hiscott, J. Transcriptional profiling of interferon regulatory factor 3 target genes: Direct involvement in the regulation of interferon-stimulated genes. J. Virol. 2002, 76, 5532-5539.

5. Kumar, K.P.; McBride, K.M.; Weaver, B.K.; Dingwall, C.; Reich, N.C. Regulated nuclear-cytoplasmic localization of interferon regulatory factor 3, A subunit of double-stranded RNA-activated factor 1. Mol. Cell Biol. 2000, 20, 4159-4168.

6. Navarro, L.; Mowen, K.; Rodems, S.; Weaver, B.; Reich, N.; Spector, D.; David, M. Cytomegalovirus activates interferon immediate-early response gene expression and an interferon regulatory factor 3-containing interferon-stimulated response element-binding complex. Mol. Cell Biol. 1998, 18, 3796-3802.

7. Wathelet, M.G.; Lin, C.H.; Parekh, B.S.; Ronco, L.V.; Howley, P.M.; Maniatis, T. Virus infection induces the assembly of coordinately activated transcription factors on the IFN-beta enhancer in vivo. Mol. Cell 1998, 1, 507-518.

8. Servant, M.J.; ten Oever, B.; LePage, C.; Conti, L.; Gessani, S.; Julkunen, I.; Lin, R.; Hiscott, J. Identification of distinct signaling pathways leading to the phosphorylation of interferon regulatory factor 3. J. Biol. Chem. 2001, 276, 355-363. 
9. Servant, M.J.; Grandvaux, N.; Hiscott, J. Multiple signaling pathways leading to the activation of interferon regulatory factor 3. Biochem. Pharmacol. 2002, 64, 985-992.

10. Chen, H.; Jiang, Z. The essential adaptors of innate immune signaling. Protein Cell 2012, doi:10.1007/s13238-012-2063-0.

11. Janeway, C.A., Jr.; Medzhitov, R. Innate immune recognition. Annu. Rev. Immunol. 2002, 20, 197-216.

12. Kawai, T.; Akira, S. The role of pattern-recognition receptors in innate immunity: Update on Toll-like receptors. Nat. Immunol. 2010, 11, 373-384.

13. Takeuchi, O.; Akira, S. Pattern recognition receptors and inflammation. Cell 2010, 140, 805-820.

14. Medzhitov, R. Recognition of microorganisms and activation of the immune response. Nature 2007, 449, 819-826.

15. Hacker, H.; Redecke, V.; Blagoev, B.; Kratchmarova, I.; Hsu, L.C.; Wang, G.G.; Kamps, M.P.; Raz, E.; Wagner, H.; Hacker, G.; et al. Specificity in Toll-like receptor signalling through distinct effector functions of TRAF3 and TRAF6. Nature 2006, 439, 204-207.

16. Tseng, P.H.; Matsuzawa, A.; Zhang, W.; Mino, T.; Vignali, D.A.; Karin, M. Different modes of ubiquitination of the adaptor TRAF3 selectively activate the expression of type I interferons and proinflammatory cytokines. Nat. Immunol. 2010, 11, 70-75.

17. Fitzgerald, K.A.; McWhirter, S.M.; Faia, K.L.; Rowe, D.C.; Latz, E.; Golenbock, D.T.; Coyle, A.J.; Liao, S.M.; Maniatis, T. IKKepsilon and TBK1 are essential components of the IRF3 signaling pathway. Nat. Immunol. 2003, 4, 491-496.

18. Sharma, S.; tenOever, B.R.; Grandvaux, N.; Zhou, G.P.; Lin, R.; Hiscott, J. Triggering the interferon antiviral response through an IKK-related pathway. Science 2003, 300, 1148-1151.

19. Hemmi, H.; Takeuchi, O.; Sato, S.; Yamamoto, M.; Kaisho, T.; Sanjo, H.; Kawai, T.; Hoshino, K.; Takeda, K.; Akira, S. The roles of two IkappaB kinase-related kinases in lipopolysaccharide and double stranded RNA signaling and viral infection. J. Exp. Med. 2004, 199, 1641-1650.

20. Sato, M.; Suemori, H.; Hata, N.; Asagiri, M.; Ogasawara, K.; Nakao, K.; Nakaya, T.; Katsuki, M.; Noguchi, S.; Tanaka, N.; et al. Distinct and essential roles of transcription factors IRF-3 and IRF-7 in response to viruses for IFN-alpha/beta gene induction. Immunity 2000, 13, 539-548.

21. Jiang, X.; Kinch, L.N.; Brautigam, C.A.; Chen, X.; Du, F.; Grishin, N.V.; Chen, Z.J. Ubiquitin-induced oligomerization of the RNA sensors RIG-I and MDA5 activates antiviral innate immune response. Immunity 2012, 36, 959-973.

22. Zeng, W.; Sun, L.; Jiang, X.; Chen, X.; Hou, F.; Adhikari, A.; Xu, M.; Chen, Z.J. Reconstitution of the RIG-I pathway reveals a signaling role of unanchored polyubiquitin chains in innate immunity. Cell 2010, 141, 315-330.

23. Kumar, H.; Kawai, T.; Akira, S. Pathogen recognition by the innate immune system. Int. Rev. Immunol. 2011, 30, 16-34.

24. Kawai, T.; Takahashi, K.; Sato, S.; Coban, C.; Kumar, H.; Kato, H.; Ishii, K.J.; Takeuchi, O.; Akira, S. IPS-1, An adaptor triggering RIG-I- and Mda5-mediated type I interferon induction. Nat. Immunol. 2005, 6, 981-988.

25. Seth, R.B.; Sun, L.; Ea, C.K.; Chen, Z.J. Identification and characterization of MAVS, A mitochondrial antiviral signaling protein that activates NF-kappaB and IRF 3. Cell 2005, 122, 669-682. 
26. Meylan, E.; Curran, J.; Hofmann, K.; Moradpour, D.; Binder, M.; Bartenschlager, R.; Tschopp, J. Cardif is an adaptor protein in the RIG-I antiviral pathway and is targeted by hepatitis $\mathrm{C}$ virus. Nature 2005, 437, 1167-1172.

27. Xu, L.G.; Wang, Y.Y.; Han, K.J.; Li, L.Y.; Zhai, Z.; Shu, H.B. VISA is an adapter protein required for virus-triggered IFN-beta signaling. Mol. Cell 2005, 19, 727-740.

28. Kumar, H.; Kawai, T.; Kato, H.; Sato, S.; Takahashi, K.; Coban, C.; Yamamoto, M.; Uematsu, S.; Ishii, K.J.; Takeuchi, O.; et al. Essential role of IPS-1 in innate immune responses against RNA viruses. J. Exp. Med. 2006, 203, 1795-1803.

29. Sun, Q.; Sun, L.; Liu, H.H.; Chen, X.; Seth, R.B.; Forman, J.; Chen, Z.J. The specific and essential role of MAVS in antiviral innate immune responses. Immunity 2006, 24, 633-642.

30. Adachi, O.; Kawai, T.; Takeda, K.; Matsumoto, M.; Tsutsui, H.; Sakagami, M.; Nakanishi, K.; Akira, S. Targeted disruption of the MyD88 gene results in loss of IL-1- and IL-18-mediated function. Immunity 1998, 9, 143-150.

31. Schwartz, A.L.; Malgor, R.; Dickerson, E.; Weeraratna, A.T.; Slominski, A.; Wortsman, J.; Harii, N.; Kohn, A.D.; Moon, R.T.; Schwartz, F.L.; et al. Phenylmethimazole decreases Toll-like receptor 3 and noncanonical Wnt5a expression in pancreatic cancer and melanoma together with tumor cell growth and migration. Clin. Cancer Res. 2009, 15, 4114-4122.

32. McCall, K.D.; Harii, N.; Lewis, C.J.; Malgor, R.; Kim, W.B.; Saji, M.; Kohn, A.D.; Moon, R.T.; Kohn, L.D. High Basal Levels of Functional Toll-Like Receptor 3 (TLR3) and Non-Cannonical Wnt5a Are Expressed in Papillary Thyroid Cancer (PTC) and Are Coordinately Decreased by Phenylmethimazole Together with Cell Proliferation and Migration. Endocrinology 2007, 148, $4226-4237$.

33. Harii, N.; Lewis, C.; Vasko, V.; McCall, K.; Benavides-Peralta, U.; Sun, X.; Ringel, M.; Saji, M.; Kohn, L. Thyrocytes express a functional toll-like receptor 3(TLR3): Overexpression can be induced by viral infection, Reversed by Phenylmethimazole, and is associated with Hashimoto's autoimmune thyroiditis. Mol. Endocrinol. 2005, 19, 1231-1250.

34. Jacobson, D.L.; Gange, S.J.; Rose, N.R.; Graham, N.M. Epidemiology and estimated population burden of selected autoimmune diseases in the United States. Clin. Immunol. Immunopathol. 1997, 84, 223-243.

35. McCall, K.D.; Holliday, D.; Dickerson, E.; Wallace, B.; Schwartz, A.L.; Schwartz, C.; Lewis, C.J.; Kohn, L.D.; Schwartz, F.L. Phenylmethimazole blocks palmitate-mediated induction of inflammatory cytokine pathways in 3T3L1 adipocytes and RAW 264.7 macrophages. J. Endocrinol. 2010, 207, 343-353.

36. Benavides, U.; Gonzalez-Murguiondo, M.; Harii, N.; Lewis, C.J.; Schwartz, A.L.; Giuliani, C.; Napolitano, G.; Dagia, N.M.; Malgor, R.; McCall, K.D.; et al. Phenylmethimazole inhibits production of proinflammatory mediators and is protective in an experimental model of endotoxic shock*. Crit. Care Med. 2012, 40, 886-894.

37. Michelsen, K.S.; Doherty, T.M.; Shah, P.K.; Arditi, M. TLR signaling: An emerging bridge from innate immunity to atherogenesis. J. Immunol. 2004, 173, 5901-5907.

38. Beutler, B. Inferences, Questions and possibilities in Toll-like receptor signalling. Nature 2004, 430, 257-263. 
39. Doyle, S.E.; O’Connell, R.; Vaidya, S.A.; Chow, E.K.; Yee, K.; Cheng, G. Toll-like receptor 3 mediates a more potent antiviral response than Toll-like receptor 4. J. Immunol. 2003, 170, $3565-3571$.

40. Wen, L.; Peng, J.; Li, Z.; Wong, F.S. The effect of innate immunity on autoimmune diabetes and the expression of Toll-like receptors on pancreatic islets. J. Immunol. 2004, 172, 3173-3180.

41. Devendra, D.; Eisenbarth, G.S. Interferon alpha-A potential link in the pathogenesis of viral-induced type 1 diabetes and autoimmunity. Clin. Immunol. 2004, 111, 225-233.

42. Michelsen, K.S.; Wong, M.H.; Shah, P.K.; Zhang, W.; Yano, J.; Doherty, T.M.; Akira, S.; Rajavashisth, T.B.; Arditi, M. Lack of Toll-like receptor 4 or myeloid differentiation factor 88 reduces atherosclerosis and alters plaque phenotype in mice deficient in apolipoprotein E. Proc. Natl. Acad. Sci. USA 2004, 101, 10679-10684.

43. Pasterkamp, G.; Van Keulen, J.K.; de Kleijn, D.P. Role of Toll-like receptor 4 in the initiation and progression of atherosclerotic disease. Eur. J. Clin. Invest. 2004, 34, 328-334.

44. Andonegui, G.; Bonder, C.S.; Green, F.; Mullaly, S.C.; Zbytnuik, L.; Raharjo, E.; Kubes, P. Endothelium-derived Toll-like receptor-4 is the key molecule in LPS-induced neutrophil sequestration into lungs. J. Clin. Invest. 2003, 111, 1011-1020.

45. Fiocchi, C. Inflammatory bowel disease: etiology and pathogenesis. Gastroenterology 1998, 115, 182-205.

46. Kohn, L.D.; Goetz, D.J.; McCall, K.D.; Schwartz, A.L.; Schwartz, F.L.; Malgor, R. Methods and compositions for the treatment of melanoma and pancreatic cancer. U.S. Patent 11/130,922, 2008.

47. Lieber, M.; Mazzetta, J.; Nelson-Rees, W.; Kaplan, M.; Todaro, G. Establishment of a continuous tumor-cell line (panc-1) from a human carcinoma of the exocrine pancreas. Int. J. Cancer 1975, $15,741-747$.

48. Graham, F.L.; Smiley, J.; Russell, W.C.; Nairn, R. Characteristics of a human cell line transformed by DNA from human adenovirus type 5. J. Gen. Virol. 1977, 36, 59-74.

49. Basler, C.F.; Mikulasova, A.; Martinez-Sobrido, L.; Paragas, J.; Muhlberger, E.; Bray, M.; Klenk, H.D.; Palese, P.; Garcia-Sastre, A. The Ebola virus VP35 protein inhibits activation of interferon regulatory factor 3. J. Virol. 2003, 77, 7945-7956.

50. Iwamura, T.; Yoneyama, M.; Yamaguchi, K.; Suhara, W.; Mori, W.; Shiota, K.; Okabe, Y.; Namiki, H.; Fujita, T. Induction of IRF-3/-7 kinase and NF-kappaB in response to double-stranded RNA and virus infection: common and unique pathways. Genes Cells 2001, 6, 375-388.

51. Servant, M.J.; Grandvaux, N.; tenOever, B.R.; Duguay, D.; Lin, R.; Hiscott, J. Identification of the minimal phosphoacceptor site required for in vivo activation of interferon regulatory factor 3 in response to virus and double-stranded RNA. J. Biol. Chem. 2003, 278, 9441-9447.

Sample Availability: Samples of the compound (C10) are available from the Interthyr Corporation.

(C) 2012 by the authors; licensee MDPI, Basel, Switzerland. This article is an open access article distributed under the terms and conditions of the Creative Commons Attribution license (http://creativecommons.org/licenses/by/3.0/). 